\title{
Fundamental Elements of the Strategy Concept
} "It is a little dark secret that most executives don't actually
know what all the elements of a strategy statement are, which
makes it impossible for them to develop one".

(Collis and Rukstad 2008; Collins 2001)

"What actually consists a strategy is missing. The key is achieving a robust, reinforced consistency among the elements of the strategy itself".

(Hambrick and Fredrickson 2001)

\subsection{Overview}

Although there are nearly 90 definitions of strategy concepts in the strategy discipline, answers to the questions of "what is strategy" are controversial academically. In the previous chapter, we examined why there are so many definitions and the reasons for having the problem of the Three-multiple problems in the literature definitions on the strategy concept.

Some scholars (Hambrick and Frodrideson 2001; Ketchen et al. 2008; Leontiades 1982; Markides 2004; Nag et al. 2007; Oliver 2001) believe that we actually know neither what exactly strategy is, nor which elements should be included in the strategy definition. This paper will elaborate on "what is a strategy". Differ from the answer to providing specific managerial suggestion to company's strategy; this chapter interprets the strategy concept from its main components and their relationship point of view. It explains what fundamental elements are included in the definition, and what the linkage is between them from the perspective of definition.

So, what is strategy? What are the fundamental elements of the strategy concept? Throughout the company's various strategies, whether it is trying to gain a competitive advantage, or one wants to enter the high-end market, or one wants to resist the pressure from alternative products in market, or one wants to meet the challenges 
from low-end market competitors, we can find that any complete strategy includes three basic elements. They are development goal (or strategic goal), major development issue (or strategic issue), and guideline (or strategic approach). ${ }^{1}$

What do those three elements mean? How do they relate and constitute the strategic concept and definition? Let us look at a few examples first.

\subsection{Examples of Companies}

\section{(1) Taobao's early competitive strategy}

In 2002, P2P personal online trading platforms were in the early stage in China and Jack Ma, CEO of Alibaba, decided to enter the industry in 2003 after he saw the development potential of China's market. However, a company from the United States, eBay entering the industry earlier had a leading advantage, and achieved great success in the Chinese market with a $70 \%$ market share. How did Taobao compete with eBay as a later player? What was its competitive strategy?

We can learn from Taobao's business model that Taobao's strategic goal was quite clear at that time that was, successfully gaining the market share from eBay. The strategic issue for Taobao at that time was what kind of platform could be appeal to customer and would be more competitive than eBay. Taobao introduced a platform which was cheaper (the price was zero) and had better service (strategic approach of Value for Money) than eBay. The platform provided buyers and sellers a direct communication channel. There exists distrust matter in payment transactions between buyers and sellers and the Ali-pay system settles the trust problem. The platform of Taobao, compared with that of eBay, had obvious advantages and attracted many Chinese users. The market share of eBay decreased from 80 to $29 \%$ by the end of 2006 (Lu Jiangyong et al. 2007).

The three elements of Taobao's competitive strategy are:

Development goal: successfully gaining the market share from eBay.

Major development issue: We have a strong competitor. What kind of platform could be appeal to customer and would be more competitive than eBay?

Overall guideline: Value for Money, cheaper (the price was zero) and better service.

\footnotetext{
${ }^{1}$ The meaning of the "major development issue" here is the same as that of the term of "a situation" in the previous chapter as mentioned by professor Mintzberg. For easier understanding, we call it "major development issue". In addition, the word itself of the name will not appear in a definition when we define something. However, when it goes to oral expression, the terms of the three elements of the strategy concept "strategic goal, strategic issue and strategic approach" are easy to read. Strategic goals are different from general goals of a company; Strategic issues are different from ordinary operation issues of a company; Strategic approaches or means, characterized by leadership and guidance, are different from ordinary approaches. The terms "strategic goal", "strategic issue" and "strategic approach, or strategic mean" appearing later in the book are "development goal, or long-term goal", "major development issue" and "guideline", respectively.
} 


\section{(2) Geely's acquisition of Volvo}

Geely is the emerging auto company, which does not rely on other companies of the auto industry. Mr. Li Shufu, the founder of Geely, had the ambition to enter high-end auto market in 2002 (the ambition can be considered as a strategic goal). There are two approaches to achieve that goal: one is that Geely can develop high-end technology independently, and promote a new Geely's high-end car brand; the other is to enter the high-end auto market by buying a mature brand. Geely could not achieve the goal no matter which way it followed in 2002 as it had neither advanced technologies nor brand and its financial strength was weak (strategic issues, or major development issues). In 2007, the United States suffered a financial crisis due to the collapse of Lehman Brothers. The economy continued to fall in 2009 and Ford experienced heavy losses. Ford planned to sell the brand of Volvo, bringing an opportunity to Li Shufu. While in 2009, Geely has accumulated enough financial resources and industry experiences after years of development. Therefore, Li Shufu decided to enter the high-end auto market by the way of acquisition (Peng and Ling 2010; Wang 2010). Geely has settled technical obstacles of entering the high-end auto market by acquisition while possesses a brand.

The three elements of the company's strategy are:

Development goal: to enter high-end auto market.

Major development issue: does not have expected technologies.

Overall guideline: acquisition.

\section{(3) Business reorganization of Kodak digital camera}

The market of digital cameras hit that of film cameras to a great extent. Kodak produced 6.3 mega-pixel digital cameras in 1991, but it lost the leading position in the digital products market due to wrong high-level decision-making. In 2002, Kodak accounted for $25 \%$ of the market share while its competitor Fuji accounted for $60 \%$. Kodak suffered great pressure coming from the success of digital products of its competitors. With declining market share and sales (those are strategic issues), Kodak hoped to change the situation and reverse the loss (strategic goal). However, due to the rapid development of the industry, the quality increased steadily while the price decreased. Therefore, Kodak cannot gain a foothold in digital cameras industry and for this reason it had several high-level personnel adjustments. In 2006, Mr. Perez proposed to maintain the status by introducing printer and stabilizing Kodak's position in the film market (strategic approach) (Gurrera 2006). At the same time, Kodak took radical measures to complete the reorganization of the company, establishing a digital business while successfully aborting some traditional areas, shutting down 13 manufacturers and 130 processing laboratories, and in total cutting about 4.7 million people (further strategic approaches, measures). The company's performance continued to decline in 2011 - share price fell by $88 \%$, and debt reached 6.8 billion dollars, which was more than the company's asset of 5.1 billion dollars (the new strategic issue). The company filed for bankruptcy protection on January 19, 2012 (a further strategic 
approach) in order to maximize the interests of shareholders, employees, retirees, creditors and pension trustees and take the interests of the most valuable customers into consideration (the strategic goal after the new issue) (Li Guimin 2012).

The three elements of Kodak's strategy are:

Development goal: change the situation and reverse the loss.

Major development issue: (1) declining market share and sales due to competition from digital cameras and (2) performance continued to decline late.

Guideline: (1) maintain the status by introducing printer and stabilizing Kodak's position in the film market, in early stage and (2) reorganization of the company, aborting some traditional areas in late stage.

\section{(4) SKF's differentiation}

As a leading company of the design and manufacture industry and the industry of selling bearing products, SKF faced the threat of the low-end market where its products may become ordinary with abnormally low prices (development issue) in 2006. Tom Johnstone, the president, asked the company to combine the needs of customers with the technology to produce products that meet any customers' needs, so as to achieve complete differentiation between SKF products and other products (overall guiding principle) in the industry to face the challenge from low-end market and to ensure the company' profitability (strategic goal). In order to achieve the strategic goal, the company has established five technology "platforms" at its headquarters which "connects" more than 3,000 engineers around the world to quickly solve any technical issues during product development and manufacturing (Marsh 2007). ${ }^{2}$

The three elements of SKF's strategy are as following:

Major development issue: threat of the low-end market where its products may become ordinary with abnormally low prices.

Development goal: ensure the company' profitability.

Overall guideline: achieve complete differentiation between SKF products and other products in the industry.

Four examples of companies' strategies are shown above. Then let us take a look at the three elements of the strategy concept of those examples.

Two of the four companies had new strategies because of new development goals, such as Taobao and Geely. Jack Ma noticed the potential of Chinese market and decided to enter the field of personal online business platform. Li Shufu wished to enter high-end auto market. The rest two companies had new strategies because they faced big problems. Kodak's main film business met the shock from digital cameras while SKF was under the threat of cheap products from low-end market.

The company strategy can be divided into goal-oriented strategy (such as the strategies of Taobao and Geely) and problem-oriented strategy (such as the strategies of Kodak and SKF) from the perspective of the origin of the strategy. Now let us look at the two types of strategies.

\footnotetext{
${ }^{2}$ According to Marsh's articles(Marsh, P. SKF: Back on a roll in the business of bearings, Financial Times, Feb 7th 2007).
} 


\subsection{Problem-Oriented Strategy}

In many cases, a company needs a strategy when it meets important problems. The company wants to fix the problems by performing the problem-oriented strategy. Problem-oriented strategy is usually generated to meet market challenges.

The order of the three elements in problem-oriented strategy is to put major s first. The order is major development issue (or strategic issue), development goal (or strategic goal), overall guideline (or strategic approach), wherein the goal generally focuses on company development. The overall guideline proposed is to provide direction to solve the development problems faced by the company. It is a basic guiding principle or an overall thought. Sometimes all the issues are likely to be solved while sometimes only part of them can be settled.

SKF actively faced challenges from the low-end market and set a goal to ensure the company's profitability. The company decided to perform complete product differentiation for meeting the challenges. To achieve the differentiation, the company established five technology-sharing platforms to realize synergistic effect on technologies around the world. We can learn from the SKF case that the major development issue ranked first among the three elements, the development goal (actively facing the challenges and ensuring profitability) and the guideline (differentiation) ranked second and third respectively.

However, Kodak had no other choice but to reduce loss by cutting staff and shutting down factories since the strategic issues it faced were much more severe than that of SKF and it had little impact on the industry of digital products at that time. The order of the three elements here is the same as SKF.

Is there any other order of the three elements in problem-oriented strategy? What about putting the major development issue first, the overall guideline second, and the goal third? The order I just mentioned exists in military strategies or company strategies. When facing development problem, not all decision-makers can find out overall guiding principle to overcome the difficulties. In this case, the goal elements may be listed in the end. In addition, the development goal may change when there is no proper overall guideline. In that situation, the goal element will be determined by the overall guideline element.

Traditionally, we have often thought that strategy is goal oriented, but the problem-oriented strategy gives us another aspect of the strategy.

The three elements of the problem-oriented strategy are shown as follow (Fig. 3.1).

We can see that, how company executives at a company performing the problem-oriented strategy consider the development issue is crucial. The major development issues are often those issues from internal and external organizations having impact on realizing the long-term goal of the company. The development issues generally derive from three aspects: competition within the industry, changes in the macro environment of the company's business, and significant changes within the company. 


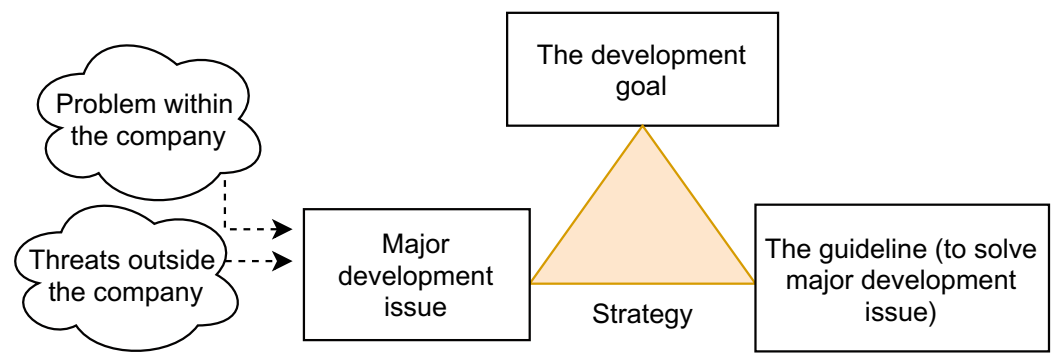

Fig. 3.1 The three elements of the problem-oriented strategy

The development issues deriving from competition within the industry generally have the following aspects:

- In the industry substitute product appears with better functions and cheaper price. For example, digital cameras substitute traditional ones, mobile phone with camera substitutes digital cameras, and network news substitutes newspapers.

- Industry competitors launch products with better quality (better technology, function, and design, etc.). For example, smart phones have great influence on non-smart phones. The industry competitors can also offer services or products with equal quality and even better quality but cheaper price. For example, Taobao offered services on its platform with better quality and cheaper price compared with that of eBay at its early stage.

- The company is hit by higher costs for key raw materials and core components while the products sell at cheaper price because of competition among the industry. For example, the steel industry in China had been suffering the pressure from the rising price of iron giants while the domestic demand and price have fallen year by year.

- The basic business models of the main competitors in the industry has changed quietly, leaving the low value-added activities to those companies that have not changed their business models or have not perceived changes in the industry. For example, the companies of the software industry tended to pursue miniaturization and third-party trading platforms appeared (such as Taobao, Misuland, ZBJ) providing services to suppliers and those in demand. However, the large companies took their sizes as a competitive advantage. The advantage was changing gradually and finally became a big development issue (inability to bear the high costs).

- New business models of an industry have greater competitive advantages and are more attractive to consumers, leaving other companies in venerable situations. For example, online shops have a great impact on physical stores and business of express companies has a great impact on that of post offices. 
- Products of suppliers belong to the monopoly industry and the main competitors has controlled the major suppliers of the industry. For example, Huawei faces with pressure recently due to trade wars and the monopoly situation of the chip industry.

The development issues deriving from the changing macro environment generally have the following aspects:

- A decline in demand for products due to slow regional economy development. For example, the United States' financial crisis in 2008 was a threat to many companies.

- The local government introduces the industry policy to curb consumer demands for the industry's products. For example, the new policy lunched by the Chinese government on real estate industry had great influence on the industry.

- The government sets lower barriers to the industry, leading to more competitors and more severe competitions. For example, the Chinese government encouraged private financing and introduced a network financial policy in 2015, which had great influence on the banking industry.

The development issues deriving from the changing inner organization of a company may have the following aspects:

- The senior managers (decision-makers) of a company cannot identify the outer threat or take effective measures.

- Important senior managers leave the company when management regulations have not been established.

- Important R\&D people leave the company and take away R\&D fellows.

- Critical sales people leave the company and take away teammates.

- A company runs on a small number of customers or suppliers.

The above is an introduction of the problem-oriented strategy. However, for many companies, they often have more development opportunities than issues in a growing economic environment.

\subsection{Goal-Oriented Strategy}

When decision-makers of a company wish to seize the chance during its development, the company needs to set a new development goal, which represents as the ambition and expectations of the decision-makers. For achieving the development goal, the company needs a strategy. The strategy produced based on the strategic goal is the goal-oriented strategy. The order of the three elements here is to put the development goal first, the major development issue second and the general guideline (to solve issues) third. 
You may wonder that the goal-oriented strategy having two of the elements, the goal and the strategic approach to the goal, would be enough as we used to believe that the strategy concept was based on those two elements. However, you will find after careful study that the overall guideline is designed particularly to solve the major development issues. That is, if you cannot identify those key issues, you cannot find out or propose a guiding principle for realizing the goal. Therefore, though the company performing the goal-oriented strategy is not facing serious development issues as those in problem-oriented strategy, it is a key step to distinguish them after deciding the development goal. That is the challenge and charm of the goal-oriented strategy.

To achieve the goal of acquiring the market share from the competitors, Taobao faced a major development issue, that is, how to attract consumers or what kind of platform will appeal to customers. Taobao created a new business model and a new platform with competitive advantages compared with eBay to solve the issue, providing better services and cheaper prices.

To achieve the goal of entering the high-end auto market, Geely faced some major development issues including no technologies, no brand, and no market recognition. However, the company solved those issues by acquiring Volvo. Acquiring Volvo helped the company solve the technology issue while get the brand, which solved the major development issue for entering the high-end auto market.

The relation among the development goal, the major issue and the overall strategy of the goal-oriented strategy is shown as follow (Fig. 3.2).

Differ from the ordinary objects; the goal of the goal-oriented strategy is often long period, relatively stable, comprehensive, divisible and full of challenges. Therefore, the goal is called development goal, long-term goal, or strategic goal.

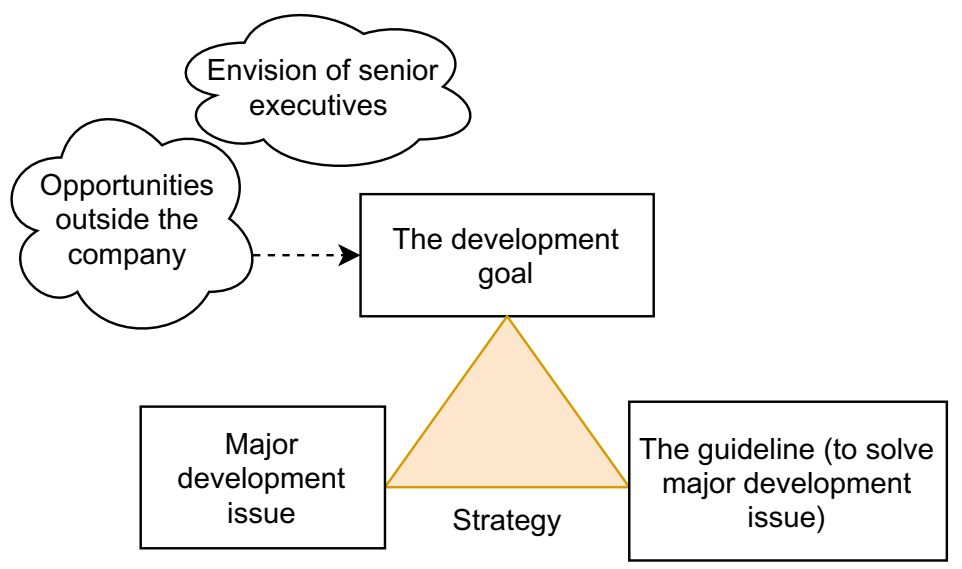

Fig. 3.2 Three elements of the goal-oriented strategy 
Different strategic goals lead to different overall guidelines while big goals or small goals determines the way in which the strategic issues are resolved and the extent to which they are resolved. If the goal of Taobao was only to enter the personal online trading platform industry and not trying to grab market share with eBay, we can image that the strategic approach of Taobao would most likely adopt the same business model as eBay. However, its goal was to set up a platform with more competitive advantages compared with eBay; therefore, its business model had a great innovation.

The strategic goal of a company represents the ideals or dreams of its decision-makers. The strategic goal is not generally achieved in a short time or by one-step but achieved with years of efforts. Therefore, it needs to be planned and implemented gradually while the company needs to prepare thoroughly (such as the decision-makers' attention, resources, financial affairs, capacity, talents of the company). If the strategic goal is taken as a routine annual one, there will be a severe shortage of resources and capabilities, or a state of weakness.

The goal plays a leading role in the goal-oriented strategy. Companies often make new strategic goals when operating conditions are good or external opportunities exist. Most companies consider better economic profit as their general strategic goals, but in the relevant literature on strategic definition, some other strategic goals are mentioned:

- Enhance the competitiveness of companies (Bowman et al. 2002; Hitt et al. 1997: p115; Porter 1996).

- Distinguish yourself from the competitors, namely, achieving product and service differentiation (Porter 1996: p38).

- Improve the company's service performance (Ronda-Pupo and Guerras-Martin 2011)

In addition to the strategic goals mentioned by literature, there are some other strategic goals:

- Expand the size of the company in the original industry (such as sales revenue improved 3 times in 5 years).

- Improve the market position and the competitive position in the original industry (such as becoming the leading company domestically, or becoming the industry leader, etc.).

- Move into new industries or new areas.

- Enter the high-end market, the middle market or the low-end market not involved before of the original industry.

- Move into new markets (new areas, new countries, etc.).

- Make competitors at a disadvantage position (by market or non-market means).

There are various strategic approaches to achieve a strategic goal. To choose which is closely related to the strategic issue faced by the company and the guiding principle of decision-makers. Li Shufu of Geely chose to acquire Volvo to enter the 
high-end auto market instead of self-developing high-end cars. Taobao chose to introduce services with better quality and cheaper prices compared with eBay to gain its competitive advantages. SKF chose differentiation to face the challenge of the low-end market. The strategic approaches of those companies are closely related to their strategic issues and the choices they made expressed the decision-makers' ideas.

You may find that when referring to "strategic approach", sometimes I call it "overall guideline" while sometimes "guiding principle". The strategic approach is different from the usual way of solving the problem. It is not specific and its main function is to guide the tactics. Therefore, the strategic approach is more of a thought rather than a concrete or detailed plan. For example, the strategic approach of Taobao was "Value for Money" and "low price with better services", which embodied the idea of how to compete with eBay while how to achieve Value for Money is the next specific plan. The chapter "Tactics and the Three Elements of the Strategy Concept" of this book has a detailed explanation about it.

We have introduced the problem-oriented strategy and the goal-oriented strategy. From the perspective of the origins of strategy, if there is no new long-term goal, there is no strategy; if there is no major development issue, there is no strategy (or no strategy is required).

\subsection{Elements of a Complete Strategy and Definition of Strategy}

It can be seen from above that, either it is a goal-oriented strategy, or a problem-oriented strategy, a complete strategy contains three basic elements. They are "development goal", "major development issue" and "guideline". The lack of any one of these elements cannot constitute a complete strategy. The strategy is a kind of overall decision-making of the three elements. The relationship of the three elements is shown as follow (Fig. 3.3).

For further understanding the three elements, let us look at a military strategy example that we introduced before.

Fig. 3.3 Three elements of a complete strategy

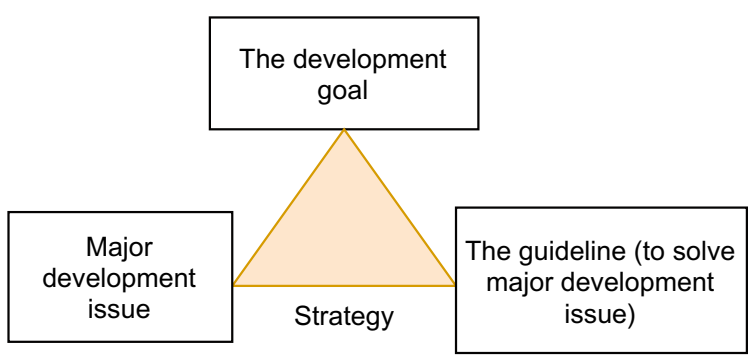


In October 1927, Chairman Mao Zedong led hundreds of people of the remaining troops in the Autumn Harvest Uprising to the middle of theJinggangshan Mountains. Though the enemy was much stronger, Chairman Mao put forward the way to lead the enemy to go around in circles, and fight against the enemy when they were tired and in a vulnerable state. In January 1928, Jiangxi Kuomintang 27th Division launched the first encirclement and suppression at Jinggangshan. At the Suichuan meeting, Chairman Mao put forward the general guideline of guerrilla warfare "I go while the enemy comes, I disturb while the enemy stays, I chase while the enemy retreats", improving the Circle tactics to the level of strategic thinking. At the following battles, based on the basic characteristics of the enemy, Chairman Mao took advantage of the favorable situations. Finally, they won the battle and established the base. Based on summing up the experience of the battle, the guideline was summarized by Chairman Mao and Commander Zhu De as "I go while the enemy comes, I disturb while the enemy stays, I fight while the enemy exhausted, I chase while the enemy retreats." The guideline opened at any time for bringing people together, but also closed at any time for fighting the enemy. ${ }^{3}$ As the basic principle of the battle, it combined back and forth, walking and fighting, as well as defense and attack. It was an effective way to save and develop strength when the enemy was much stronger.

We can show the guideline of Chairman Mao and Commander Zhu De according to the three elements ${ }^{4}$ of strategy as follows:

Development issue (element 1): Strong enemy and weak me.

Development goal (element 2): destroy the enemy while actively defend, preserve and develop our strength.

Guideline (or general principle) (element 3): I go while the enemy comes, I disturb while the enemy stays, I fight while the enemy exhausted, I chase while the enemy retreats.

Different from the left deviation thoughts, ${ }^{5}$ Chairman Mao correctly identified the force disparity between the Kuomintang (The national party) and the Communist Party at the early stage, therefore the strategic issue was characterized as "the enemy was much stronger" and the guideline was taken successfully to achieve the strategic goal of "actively defend". The guiding principle helped make flexible use of limited force of the Communist Party at that time, to avoid weaknesses and preserve force strength during the fight.

We can see from the above that the three elements are integrated dynamically. The guideline will not exist without the goal "actively defend" and the correct judgement of the situation. We can also learn that the guideline (or strategic approach) can be a thought, and that is where the strategic approach is different from other usual ways. The general guideline is expressed as a thought with the characteristics of dominance, rigidity and guidance. Though each battle was unique, the guideline played a guiding role in the specific battles. During the guerrilla

\footnotetext{
${ }_{3}^{3}$ Chairman Mao Zedong Collection Volume I, Chinese People's Publishing House, 1999, p56.

${ }^{4}$ As this is a problem oriented strategy, the element of strategic issue comes firstly.

${ }^{5}$ For details of Wang Ming's mistakes on judgement, please refer to Sect. 6.1 of Chap. 6.
} 
warfare, the commander can make flexible use of the guideline of "I go while the enemy comes, I disturb while the enemy stays, I fight while the enemy exhausted, I chase while the enemy retreats" according to the specific situation.

Therefore, whether in a business competition or in a military war, a strategy should contain the three elements, which complement each other, integrate organically and constitute a complete strategy. The lack of any of these elements will have a huge impact on strategy decision-making. In fact, the strategy with the lack of any of the elements will be incomplete. Eisehardt (1989) has pointed out that the integration of (strategic) decision-making is major as it can help senior management to analyze various options to deal with uncertainty within high-risk decision-making, while the lack of integrated decision-making will make them in a state of anxiety.

The theory of three elements of the strategy concept answers three major questions. What are the fundamental elements of strategy? How are the elements integrated? What is strategy? It also solves the problem of what strategic decision-making integrates and finds the specific integrated content in it, which helps us do better strategic decision-making.

Thus, we can define the strategy as follows: strategy is an overall guideline, which guides the tactics, in order to solve organization major development issues in achieving its development goal.

\subsection{Incomplete Strategies}

What the strategy will be if lacking in any element. Let us start with a strategy that lacks the element of purpose.

As we mentioned earlier, from their origins, there are goal-oriented and problem-oriented strategies. For a goal-oriented strategy, the goal comes from the origin of strategic needs. If there is no goal, there will not be a need of a strategy. Therefore, the goal is the origin of demand for strategy.

For a problem-oriented strategy, a company has encountered bottlenecks in its development and needs a strategy, where a goal is still crucial to solve the development issues. In the case of SKF, assume the company did not have a goal when the company was facing market challenge, the company would lose its direction. In addition, it is not likely the company would have an active counterattack to the treats from the market. SKF's goal was "maintain profitability". The executive of the company proposed the guiding principle of "high differentiation" by taking the company's advantage in technology for resolving the development issue.

What will it be if the strategic decision-making has no long-term goal for a company's development?

In a military war, what will you do when your enemy is much stronger? The general guideline or strategic approaches will be different according to the goal of "actively defend" or "give up". Is it possible to have no goal? Obviously not. Imagine that you are the commander, how will you lead the soldiers without a goal? 
That is like saying, "Soldiers, all up to you", which makes them confused. The same is true of corporate strategy.

Therefore, the strategy without the element of a strategic goal is undirected, groping along without any preconceived goal. That is, the strategy with the elements of strategic issues and approaches but without the element of a strategic goal is undirected (Fig. 3.4).

What would a strategy like without the element of overall guiding ideology?

As we have described earlier, the overall guideline is designed specifically to address major development issues. If a strategy does not have the element of guideline, it will lack of principles guiding the solving of major development issues. If major problems cannot be effectively resolved, the strategic objectives may only be shelved and will never be realized. Therefore, the strategy of lacking the element of guiding ideology is a "Utopia" strategy (Fig. 3.5).

In the traditional sense, the term strategy refers to the overall idea of overcoming obstacles to achieve goals. Therefore, if you do not have the overall idea, it means you have no strategy at all.

In the case of Taobao, if Jack Ma and his team had not designed or thought of a personal online trading platform that had better competitive advantages favored by Chinese customers than eBay, gaining the market share from eBay would be impossible and became an empty talk.

Then what will it be if a strategy has no element of major development issue?

For a problem-oriented strategy, a company has encountered bottlenecks in its development and needs a strategy. Therefore, from the origin of strategy, if there is no major development problem, there is no need for strategy.

Fig. 3.4 The

undirected strategy (without a strategic goal)

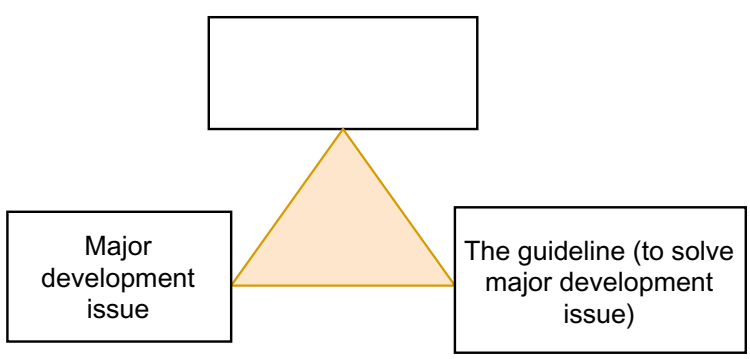

Fig. 3.5 The utopian strategy (without guideline)

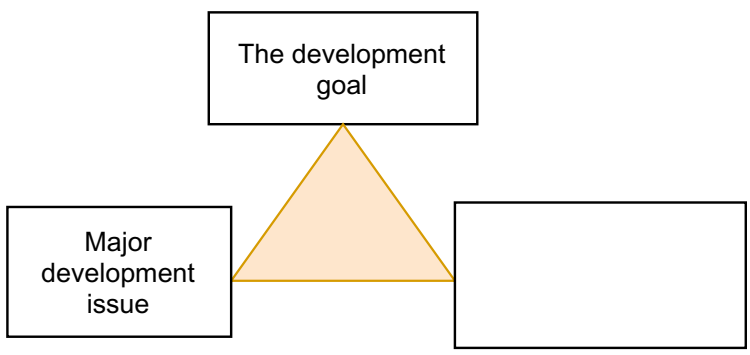


For goal-oriented strategy, traditionally, we believe that a goal-oriented strategy requires only two elements of "goal" and "guideline". However, without the element of "major development issue", the proposition of guiding ideology will lack its foundation.

We know that if the goals are different, the key issues along the way will be different, and the overall guidelines will not be the same. However, even with the same goal, there could be various ways to achieve it. Let us take a daily example. I live in Shanghai. Suppose I am traveling and my goal is Beijing. Ways to get there can include by air, by high-speed train, by ordinary train, or by bus and coach. It is not likely that every approach is suitable with me. If I am desperately lack of money, I may chose taking ordinary train to go to Bejing as this is cheap and safe. If both money and time are not problems, I may select high-speed train. In this example, you may say that the final selected approach depend on my judgement on my own situation. You are then right; the judgement is exactly the element of the identification of the "major issue". Without the judgment of the situation, it will be hard to choose appropriate approach to go to Beijing.

For strategy, the choice of guiding principle depends on the level of development goals. It also depends on decision makers' perception, identification and understanding of company's major development issues. If key issues are unknown or are unclear, it indicates that company executives cannot identify the nature of the company's development problem.

Early we mentioned the 16-word principles, which are "I go while the enemy comes, I disturb while the enemy stays, I fight while the enemy exhausted, I chase while the enemy retreats". We know that Chairman Mao and the early revolutionaries in China could not have developed the guerrilla warfare guideline if they had not clearly identified and understood the situations in the early revolution stage. Similarly, if Jack Ma had not clearly understood what key problems the personal online trading platform would face, he and his team would not have been successful in designing the more competitive business model.

Thus, a strategy with only a strategic goal and approaches is a "confusing" one (or bewildered one) (Fig. 3.6).

Fig. 3.6 The confusing strategy (without major development issue)

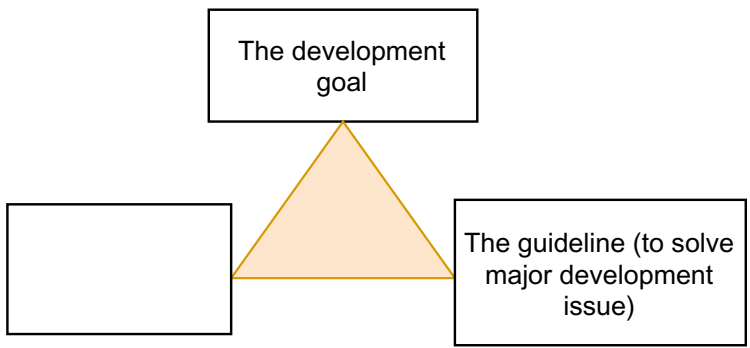




\subsection{Conclusions}

To know what is a strategy is the basis of the strategic management discipline. We will not be able to formulate a strategy if we do not know what it is. Only if we have understood the nature of the strategy concept, we can learn what a strategy should consist of as a critical decision.

This chapter introduces the theory of three elements of the strategy concept. It answered the question of what elements a strategy includes (Collins 2001; Huambrick and Fredrickson 2001; Collis and Rukstad 2008). A strategy includes three fundamental elements. They are "development goal", "major development issue" and "guideline or guiding principle".

This chapter also provides the solution to the question by Leontiades (1982); Hambrick and Fredrickson (2001); Markides (2004); Nag (2007); and Ketchen et al (2008) of what is the relationship between strategic elements. The three elements are integrated to form a complete strategy. Lack of any one will cause incomplete strategy. A strategy without "development goals" is undirected and one that cannot identify "development problems" is confusing, while one without a "general ideology" is unrealistic.

This chapter also answers the question of "what is a strategy" (Hambrick and Frodrideson 2001; Ketchen et al. 2008; Leontiades 1982; Markides 2004; Nag et al. 2007; Oliver 2001) that has been haunting for more than half a century.

\section{References}

Bowman, E. H., Singh, H. \& Thomas, H. (2002). The domain of strategic management: history and evolution. In Handbook of Strategy and Management. Pettigrew A, Thomas H, Whittington R (Eds). London: Sage.

Collis, D. J., \& Rukstad, M. G. (2008). Can you say what your strategy is? Harvard Business Review, 86(4), 82-90.

Collins, H. M. (2001). Tacit knowledge, trust and the Q of sapphire. Social Studies of Science, 31 (1), 71-85.

Eisenhardt, K. M. (1989). Making fast strategic decisions in high-velocity environment. Academy of Management Journal, 32(3), 543-576.

Gurrera, F. (2006, Nov 29). Kodak refocuses on digital age. Retrieved from https://www.ft.com/ content/0c26130a-7eff-11db-b193-0000779e2340.

Hambrick, D. C., \& Ferdrickson, J. W. (2001). Are you sure you have a strategy? Academy of Management Executive, 15(4), 48-59.

Hitt, M. A., Hoskisson, R. E., \& Kim, H. (1997). International diversification: Effects on innovation and firm performance in product-diversified firms. Academy of Management Journal, 40, 767-798.

Ketchen, D. J., Boyd, B. K., \& Bergh, D. D. (2008). Research methodology in strategic management: Past accomplishments and future challenges. Organizational Research Methods, $11(4), 643-658$.

Leontiades, M. (1982). The confusing words of business policy. Academy of Management Review, $7(1), 45-48$. 
Li, G. (2012, January 19). Kodak formally applied for bankruptcy protection. Century old store lost its grip on digital age. NetEase Finance and economics. Retrieved from https://money.163. com/12/0119/13/7O4T5ROT002526O3.html.

Lu, J. Y. \& Tao, Z. G. (2007). Ebay's strategy in China: Alliance or acquisition. Asia Case research Center.

Markides, C. (2004). What is strategy and how do you know if you have one? Business Strategy Review, 15(2), 5-12.

Marsh, P. (2007, Feb 7). SKF: Back on a roll in the business of bearings. Retrieved from https:// www.ft.com/content/fb84e7c2-b5fb-11db-9eea-0000779e2340.

Nag, R., Hambrick, D. C., \& Chen, M. J. (2007). What is strategic management, really? Inductive derivation of a consensus definition on the field. Strategic Management Journal, 28(9), 935955.

Oliver, R. W. (2001). What is strategy, anyway? Journal of Business Strategy, 22(6), 7-10.

Peng, X., \& Lin, J. (2010, March 31). Li Shufu: Volvo will not have Geely production. Morning news. Retrieved from https://auto.sohu.com/20100331/n271223604.shtml.

Porter, M. E. (1996). What is strategy? Harvard Business Review, 74(6), 61-78.

Ronda-Pupo, G. A., \& Guerras-Martin, L. A. (2011). Dynamics of the evolution of the strategy concept 1962-2008: A co-word analysis. Strategic Management Journal, 33, 162-188.

Wang, H. F. (2010, March 30). Li Shufu: Volvo can't be bought with money. Retrieved from https://auto.sohu.com/20100330/n271212437.shtml.

Open Access This chapter is licensed under the terms of the Creative Commons Attribution 4.0 International License (http://creativecommons.org/licenses/by/4.0/), which permits use, sharing, adaptation, distribution and reproduction in any medium or format, as long as you give appropriate credit to the original author(s) and the source, provide a link to the Creative Commons license and indicate if changes were made.

The images or other third party material in this chapter are included in the chapter's Creative Commons license, unless indicated otherwise in a credit line to the material. If material is not included in the chapter's Creative Commons license and your intended use is not permitted by statutory regulation or exceeds the permitted use, you will need to obtain permission directly from the copyright holder.

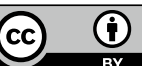

